\title{
Audit of cardiac catheterisation in a district general hospital: implications for training
}

\author{
L D R Smith, G Spyer, J W Dean
}

\begin{abstract}
Objective-To assess complications of diagnostic cardiac catheterisation in a nonsurgical centre by review of the first three years' experience and audit of 2804 diagnostic left heart procedures.

Design-Analysis of a prospective database of cardiac catheter procedures.

Setting-District general hospital without available on site cardiac surgery.

Results-The rate of major complications of cardiac catheterisation was $0.07 \%$. Mortality was $0.07 \%$, and the rate of arterial complications (requiring surgical repair) was $0.24 \%$ for brachial arteries and $0.17 \%$ for femoral. These results are comparable to those reported from national and international surgical centres.

Conclusion-A diagnostic cardiac catheterisation service can be offered in non-surgical hospitals without an increased risk to patients. It highlights the relevance of training in angioplasty and questions the appropriateness of starting preliminary invasive cardiology training of specialist registrars in district general hospitals.

(Heart 1999;81:461-464)
\end{abstract}

Keywords: cardiac catheterisation; complications; specialist training; district general hospital

Cardiac catheterisation in a district general hospital (DGH) enables increased numbers of patients to be investigated, reduces waiting times, and as a local service brings the advantages of access and communication. Expansion to DGHs has come in the wake of increased awareness of the benefits of coronary intervention, the health service internal market, and the appointment of those trained in invasive cardiology to non-surgical centres. Despite the described benefits concern has been expressed about patient safety. Some cardiologists have cautioned against the development of catheter facilities without available surgery, most notably in an audit review from a London tertiary referral hospital in $1990 .{ }^{1}$ The authors reported the need for immediate surgical intervention for "profound circulatory collapse during the procedure" in $0.24 \%$ of 5781 "low risk" patients undergoing "routine" left heart catheterisation. Overall mortality was $0.07 \%$, but they considered that mortality would probably have been higher if "high risk" patients had been included. They concluded that patients are at risk without on site emergency surgery. Catheterisation in DGHs has been practised in a few centres for more than 20 years, but there have been few reports of outcome. ${ }^{2}$ We found no publication of a substantial audit of activity from any one centre or collection of centres that could be used to confirm or refute the concerns of many cardiologists. In this article we review our three year experience of catheterisation without available surgery and present audit data on 2804 diagnostic left heart procedures.

\section{Operational background}

The Royal Devon and Exeter Hospital cardiology department provides diagnostic cardiac catheterisation for a population of approximately 480000 from the surrounding district of north and east Devon: the per capita catheterisation rate is in accord with European recommendations. ${ }^{3}$ Most outpatients are seen by a consultant in the outpatient department before catheterisation but there is no specific pre-catheter clinic. The dedicated cardiac catheterisation laboratory lies within the cardiac department and is a state of the art digital coronary angiography suite (Philips Medical Systems). Diagnostic catheterisation is performed without routine premedication as a day case elective procedure in patients with suspected heart disease and includes left heart studies predominantly for ischaemic heart disease, right and left studies for intracardiac shunts, valve disease, heart transplant investigation, as well as diagnostic and therapeutic electrophysiological procedures. Most outpatient (day case) procedures are performed through the brachial route using the Miller technique, ${ }^{4}$ a modified Judkins technique being used in patients with inappropriate brachial anatomy and those with previous internal mammary artery grafts. Inpatients with unstable angina, postinfarction angina, and abnormal submaximal exercise tests five days postinfarction (routine for all patients younger than 75 years surviving myocardial infarction) are also catheterised, normally by the femoral route as immediate discharge is not a consideration. Patients in a critical state have been taken to the catheter laboratory expressly for rescue or salvage percutaneous transluminal coronary angioplasty (PTCA) or primary angioplasty. Images are recorded simultaneously in digital and Super VHS video formats. They are reported in digital format and the ejection fraction is routinely calculated using online manufacturer's software incorporating the centre line method of Sheehan et al. ${ }^{5}$

Total permanent catheter laboratory personnel include two cardiac technicians, three nurses, and two consultants with one additional session devoted to a visiting consultant. 
Table 1 Procedure times and $x$ ray doses

\begin{tabular}{lllllll}
\hline & \multicolumn{2}{l}{ Without grafts } & & \multicolumn{2}{l}{ With grafts } & \\
\cline { 2 - 3 } \cline { 5 - 6 } & Brachial & Femoral & & Brachial & Femoral \\
\hline Procedure time (median) (mins) & 14 & 12 & & 22 & 23 \\
Screening time (median) (mins) & 2.5 & 2.6 & & 6.3 & 9.1 \\
$x$ ray dose $\left(\mathrm{Gycm}^{2}\right)$ & 101 & 85 & & 226 & 248 \\
\hline
\end{tabular}

Table 2 Breakdown of 3000 cardiac catheter procedures

\begin{tabular}{lrc}
\hline Procedure & Number & $\%$ \\
\hline Left heart study & 2804 & 93.4 \\
Left and right study & 84 & 2.83 \\
Rescue PTCA & 45 & 1.53 \\
EXPAPS primary PTCA & 64 & 2.1 \\
Right heart only & 3 & 0.1 \\
\hline
\end{tabular}

EXPAPS, Exeter primary angioplasty pilot study. ${ }^{5}$

There are no radiographers or porters. A fully trained research registrar has also operated and a full time associate specialist has been trained during the last three years. Eighty per cent of the investigations have been performed by the two resident consultants. Radiation exposure is monitored by the radiation protection officer and the hospital physics department; exposure has always been within acceptable limits. Procedure times are recorded as time from skin incision to catheter withdrawal and do not include time to haemostasis whether by repair or compression. Screening time is recorded automatically as is the total $x$ ray dose at the image intensifier in $\mathrm{Gycm}^{2}$. Table 1 summarises procedure times, screening times, and $x$ ray dose. Values are for left heart catheterisation including patients with aortic stenosis, most of whom were outpatients investigated by the brachial route.

\section{Methods}

Data were derived from analysis of a prospective database of cardiac catheter procedures based on a commercially available system (Summit Medical, Minneapolis, USA) that was updated after each procedure (pacemaker implantation and electrophysiological studies are recorded on a different database). We reviewed the first 3000 procedures (table 2), identifying 2804 diagnostic left heart investigations. Cardiac catheterisation was performed on a routine basis in outpatients and on inpatients with unstable angina, postinfarction angina, or postinfarction and abnormal exercise tests before discharge. Critically unwell patients with pulmonary oedema, cardiogenic shock, or failed thrombolysis who had left heart catheterisation for rescue or salvage angioplasty were excluded. Patients with acute myocardial infarction who entered the Exeter primary angioplasty pilot study reported elsewhere were also excluded. ${ }^{6}$

\section{Results}

Between April 1994 and June 1997, 3000 cardiac catheterisations were performed in our catheter laboratory. A total of 2804 were diagnostic left heart procedures: 2124 were routine day case procedures, 1576 by the brachial route and 548 by the femoral route, and 680 were inpatient studies in those with unstable coronary syndromes, most of whom (91\%) were catheterised by the femoral route. The age range for outpatients was 16 to 92 (mean 62.7) years and for inpatients it was 30 to 88 (mean 63.4) years, with $72 \%$ male preponderance in both groups. The ejection fraction ranged from $7 \%$ to $91 \%$ (median $65 \%$ ) for outpatients and from $10 \%$ to $89 \%$ (median $58 \%$ ) for inpatients. Tables 3 and 4 show the findings and management plan for the main outpatient and inpatient indications for catheterisation.

MORTALITY

Two patients $(0.07 \%)$ developed catheter induced profound circulatory collapse in the catheter laboratory during catheterisation and died. The first patient (aged 48 years) who underwent routine investigation as an outpatient had an immediate circulatory collapse following dissection of a severe left main stem lesion found during catheterisation from the leg. Concurrent with resuscitative manoeuvres his left main stem was opened with an angioplasty wire, balloon, and intracoronary stent restoring antegrade blood flow in the left coronary artery within 30 minutes of dissection. He died, following persistent hypotension, with intermittent and finally intractable ventricular fibrillation.

The second patient (aged 51) was a female inpatient with previously well documented myocardial infarction and unstable angina but angiographically normal vessels. The dominant right coronary artery was dissected from ostium to crux with ensuing haemodynamic collapse. The false lumen was intubated and an angioplasty guidewire and balloon were used to create a passage back into the true lumen and the wire passed distally. This procedure fully restored antegrade flow and the haemodynamics. The patient was transferred with the wire in situ 170 miles to the surgical centre where successful bypass grafting was performed the next day. Surgery was uneventful but she suffered an unexpected cardiac arrest 48 hours after operation and despite reoperation died.

Table 3 Findings for the main indications for catheterisation (\%)

\begin{tabular}{|c|c|c|c|c|c|c|}
\hline & $\begin{array}{l}\text { Normal } \\
\text { coronaries }\end{array}$ & $\begin{array}{l}\text { Single vessel } \\
\text { disease }\end{array}$ & $\begin{array}{l}\text { Double vessel } \\
\text { disease }\end{array}$ & $\begin{array}{l}\text { Triple vessel } \\
\text { disease }\end{array}$ & $\begin{array}{l}\text { Diseased } \\
\text { bypass grafts }\end{array}$ & $\begin{array}{l}\text { Left main stem } \\
\text { disease }\end{array}$ \\
\hline \multicolumn{7}{|l|}{ Outpatient } \\
\hline Chronic stable angina & 7.2 & 19.1 & 27 & 42.1 & 5.3 & 7.9 \\
\hline New angina ( $<6$ months) & 9.1 & 28.2 & 28.6 & 32.4 & 11.5 & 8.4 \\
\hline Atypical chest pain & 78.5 & 13.6 & 4.9 & 0.7 & 0 & 0.7 \\
\hline \multicolumn{7}{|l|}{ Inpatient } \\
\hline Unstable angina & 8.3 & 23.7 & 26 & 36.7 & 7.6 & 5.7 \\
\hline Postinfarct angina & 3.8 & 29.8 & 33.3 & 30.2 & 1.6 & 3.5 \\
\hline Abnormal postinfarct exercise test & 0.6 & 34 & 34.6 & 27.6 & 0.6 & 5.8 \\
\hline
\end{tabular}


Table 4 Management plan for the main indications for catheterisation

\begin{tabular}{lccc}
\hline & PTCA (\%) & CABG (\%) & Conservative (\%) \\
\hline Outpatient & 11.3 & 40.6 & 35.5 \\
Chronic stable angina & 26.1 & 31 & 24 \\
New angina (< 6 months) & 2.1 & 1.4 & 90.6 \\
Atypical chest pain & & & \\
Inpatient & 25 & 33.1 & 34.9 \\
Unstable angina & 18.4 & 31.7 & 40.3 \\
Postinfarct angina & 10.3 & 29.5 & 51.9 \\
Abnormal postinfarct exercise test & & & \\
\hline
\end{tabular}

The remaining patients had a management plan that depended on further investigation such as perfusion scanning or further discussion with patient, family or surgeon.

Three other deaths occurred within 24 hours after catheterisation. One female inpatient (aged 77) with unstable angina tolerated the diagnostic procedure, but complete occlusion of a subtotally occluded left anterior descending artery occurred 30 minutes postprocedure. She subsequently died despite attempted rescue PTCA. A second woman (aged 79) had critical aortic stenosis and pulmonary oedema. It was decided that aortic valve replacement would be appropriate if the coronaries were normal and she underwent catheterisation. Severe coronary disease was found. She arrested and died six hours later. The third patient was a male inpatient (aged 77) with unstable angina whose coronary disease was considered to be inoperable. $\mathrm{He}$ subsequently died on the ward within 24 hours. The last two patients underwent postmortem examination. None had an identifiable catheter induced coronary dissection either during the procedure or in the subsequent angiogram in one patient or at postmortem examination in the other two.

ARTERIAL COMPLICATIONS

Of 1637 brachial procedures, four patients $(0.24 \%)$ required surgical exploration by on site vascular surgeons. None has experienced long term sequelae. Of 1167 femoral procedures, two patients $(0.17 \%)$ required surgical exploration and repair. A false aneurysm was diagnosed in a further patient 14 days later and successfully treated with compression. Six large haematoma $(0.5 \%)$ were also found in patients investigated by the femoral route but these were managed conservatively and did not require transfusion. There were two uncomplicated minor coronary dissections $(0.07 \%)$ - that is, angiographic evidence of dissection without clinical sequelae, both in the right coronary artery and five uncomplicated conduit artery dissections $(0.018 \%)$ (two femoral, two subclavian, and one iliac).

OTHER COMPLICATIONS

Four patients $(0.14 \%)$ suffered a cerebrovascular event: three had transient episodes in the laboratory and one developed a fourth nerve

Table 5 Comparative mortality rates for diagnostic left heart procedures

\begin{tabular}{lcl}
\hline Series & Patients (n) & Mortality (\%) \\
\hline Exeter & 2804 & 0.07 \\
Tertiary hospital $^{1}$ & 5781 & 0.07 \\
CECCC $^{8}$ & 28369 & 0.12 \\
\hline
\end{tabular}

CECCC, confidential enquiry into cardiac catheterisation complications. palsy that was partially corrected with prismatic treatment but with long term disability negotiating stairs.

Thirty six patients $(1.3 \%)$ had a bradycardia: 35 of whom received atropine and one $(0.036 \%)$ required temporary pacing. Patients with ventricular arrhythmia did not require cardioversion.

\section{Discussion}

The risks associated with diagnostic cardiac catheterisation have been reported in very large registry data from major American centres. ${ }^{7} 8$ The mortality risk is between $0.02 \%$ and $1.2 \%$ depending on the risk category, with overall mortality of between $0.11 \%{ }^{7}$ and $0.19 \% .^{8}$ The more recent British confidential inquiry into cardiac catheter complications reported an overall mortality of $0.12 \%$ and a surgical intervention rate of $0.08 \% .{ }^{9}$ Stewart et al $l^{1}$ reported the rate of catheter induced circulatory collapse requiring surgical intervention as $0.24 \%$ in low risk patients. The surgical intervention rate for local vascular complications has been reported as $0.3 \%$ for brachial catheterisation and $0.38 \%$ for femoral in a 10 year review from another London postgraduate teaching hospital. ${ }^{11}$

Our rate of catheter induced circulatory collapse in the laboratory was $0.07 \%$, with an overall mortality of $0.07 \%$ and a local arterial complication rate of $0.24 \%$ for brachial catheterisation and $0.17 \%$ for femoral. These values compare favourably with those from centres with on site surgery available (table 5). Unlike some non-surgical centres, patients of all clinical risk categories are catheterised and therefore a significant proportion of high risk patients with unstable coronary syndromes $(20.9 \%)$ or a low ejection fraction $(8.5 \%$ $<40 \%$ ) are included here. Therefore, audit outcome cannot be attributed to the selection of low risk patients.

There are many benefits from a cardiac surgical presence but the findings of this audit suggest that a reduction in mortality from diagnostic catheterisation is not one: mortality without surgery in Exeter being the same or less than mortality with surgery in other centres. Could cardiac surgery have saved the patients who died? The immediate surgery that would have been required is rarely available even in surgical centres, where theatres and surgeons are unlikely to be free. As a result, patients requiring cardiac massage to theatre have very high mortality. ${ }^{1}$ Nevertheless, it is possible that surgery may have prevented this death.

Coronary flow in both patients with life threatening coronary dissection was restored with angioplasty techniques, which in one enabled initially successful surgery. There is no doubt that angioplasty skills are a potentially life saving factor in diagnostic catheterisation and should be encouraged in those undertaking catheterisation without available surgery. In addition, angioplasty skills enhance the quality of the diagnostic images and improve understanding of potential revascularisation options, which are also important to impart to trainees. 
The increased availability of diagnostic facilities created by the development of catheterisation in non-surgical centres affords unstable patients requiring immediate investigation ${ }^{11} \mathrm{a}$ better chance of early revascularisation, which may offset any potential risk associated with the absence of surgery.

The rate of major and minor complications is higher when procedures are performed by trainee operators. ${ }^{12}$ Our lower rate of major complications than the rate reported by Stewart et $a l^{1}(0.07 \%$ v $0.24 \%)$ may be related to experience of the operator $(82 \%$ consultant $v 45 \%$ consultant). Recently published requirements ${ }^{13}$ for specialist registrar training in cardiology expect DGHs to train new operators in invasive procedures including cardiac catheterisation and coronary arteriography. It would seem advisable to arrange some initial invasive training in centres with additional back up facilities. Indeed, it may be more appropriate to have only experienced trainees in non-surgical centres.

CONCLUSION

This report shows that a diagnostic cardiac catheterisation service can be offered in non-surgical hospitals without an increased risk to patients and justifies the recommendation in the British Cardiac Society Council statement. ${ }^{14}$ However, because of the more exposed environment of the non-surgical centre we suggest that training in angioplasty should be encouraged for current and future district hospital cardiologists and question the wisdom of starting preliminary invasive training of specialist registrars in DGHs.

1 Stewart JT, Gray HH, Ward DE, et al. Major complications of coronary arteriography: the place of cardiac surgery. $\mathrm{Br}$ Heart F 1990;63:74-7.

2 Burrell CJ, Papaconstantinou H, Cowley ML, et al. Multi-purpose catheterisation laboratory in the district general hospital: audit of the first 250 cases [abstract]. $\mathrm{Br}$ Heart f 1994;71 (suppl 5):322.

3 Unger F. European survey on cardiac interventions, open heart surgery, PTCA, cardiac catheterisation in 1992. Report of the Institute for Cardiac Survey of the European Academy of Sciences and Arts. Annals of the European Academy of Sciences and Arts. Vol. 6. Salzburg: Academia Academy of Sciences and Arts. Vol. 6. Sal

4 Miller GAH. Invasive investigation of the heart. Oxford: Blackwell Scientific Publications, 1989:32.

5 Sheehan FH, Bolson EL, Dodge HT, et al. Advantages and applications of the centre-line method for characterising regional ventricular function. Circulation 1986;74:293305.

6 Smith LDR, Dean JW. Primary angioplasty in the district general hospital. Interim analysis of the Exeter primary angioplasty pilot study (EXPAPS) [abstract]. Heart 1997; 77 (suppl 1):150.

7 Kennedy JW Complications associated with cardiac catheterisation and angiography. Cathet Cardiovasc Diagn 1982; 8:5-11

8 Davis K, Kennedy JW, Kemp HG, et al. Complications of coronary arteriography from the collaborative study of corcoronary arteriography from the Collaborative study of cor12 .

9 de Bono D. Complications of diagnostic cardiac catheterisation: results from 34041 patients in the United Kingdom confidential enquiry into cardiac catheter comKingdom confidential enquiry into cardiar

10 Miller GAH. Local arterial complications of left heart cathMiller GAH. Local arterial complications of left heart
eterisation. $\mathcal{F}$ R Coll Physicians Lond 1986;20:288-9.

11 A report of a working group of the British Cardiac Society: cardiology in the district hospital. Br Heart F 1994;72:3038.

12 Cohen MV, Cohn PF, Hermann MV, et al. Diagnosis and prognosis of left main coronary artery obstruction abstract]. Circulation 1972;46(suppl 1):57.

13 Hall RJC, Boyle RM, Webb-Peploe M, et al. Guidelines for specialist training in cardiology. Br Heart $\mathcal{F}$ 1995;73(suppl 1): $1-24$

14 British Cardiac Society Council statement. Br Heart 7 1994; 71:110-12. 